http://dx.doi.org/10.32929/2446-8355.2019v28n4p435-451

\title{
CUSTO DE PRODUÇÃO E ANÁLISE ECONÔMICA DO ABACAXIZEIRO CULTIVAR 'PÉROLA' EM TANGARÁ DA SERRA - MT, BRASIL
}

\author{
Diego Fernando Daniel ${ }^{1 *}$, Nayara Nunes Rodrigues ${ }^{2}$, José Roberto Rambo ${ }^{3}$, Alessandro \\ Bandeira Dalbianco ${ }^{4}$
}

\footnotetext{
${ }^{1}$ Engenheiro Agrônomo, Universidade do Estado de Mato Grosso (UNEMAT), Tangará da Serra - MT, Brasil. *E-mail do autor correspondente: diegodanielmt@gmail.com

${ }^{2}$ Engenheira Agrônoma, Universidade do Estado de Mato Grosso (UNEMAT), Tangará da Serra - MT, Brasil.

${ }^{3}$ Docente, Doutor em Agronomia, Departamento de Agronomia, Universidade do Estado de Mato Grosso (UNEMAT), Tangará da Serra - MT, Brasil.

${ }^{4}$ Engenheiro Agrônomo, Mestrando do Programa de Pós-Graduação em Ambiente e Sistemas de Produção Agrícola (PPGASP), Universidade do Estado de Mato Grosso (UNEMAT), Tangará da Serra - MT, Brasil.
}

Recebido: 23/05/2019; Aceito: 02/12/2019

RESUMO: A estimativa do custo de produção para a região de estudo é de grande importância, pois auxiliará na melhoria das informações sobre a cultura, que posteriormente poderão ajudar os agricultores familiares da região na implantação e condução da cultura, assim complementando a sua renda familiar. O objetivo deste estudo de caso foi realizar a estimativa do custo de produção e a lucratividade da cultura do abacaxi, cultivar Pérola, no município de Tangará da Serra, Mato Grosso. A metodologia utilizada no trabalho é definida por Matsunaga et al. (1976), e descrita por Martin et al. (1998), onde foram determinados o custo operacional efetivo (COE), custo operacional total (COT), receita bruta (RB), lucro operacional (LO), índice de lucratividade (IL), produtividade e preço de equilíbrio. Os valores referentes ao COE e COT, corresponderam respectivamente, a $\mathrm{R} \$ 19.313,70$ e $\mathrm{R} \$ 20.279,39$. Os custos com a adubação (27,99\%), aquisição de mudas $(25,89 \%)$, tratos culturais $(11,90 \%)$ e colheita $(9,86 \%)$ foram os maiores gastos observados na produção do abacaxi. Para a comercialização efetiva, o LO da produção de abacaxi foi de $\mathrm{R} \$ 19.480,61$, com receita bruta de $\mathrm{R} \$ 39.760,00$, índice de lucratividade de 49,00\% e margem bruta de $96,06 \%$, confirmando a rentabilidade da atividade na região.

Palavras-chave: Ananas comosus (L.) Merril. Comercialização. Lucratividade.

\section{PRODUCTION COST AND ECONOMIC ANALYSIS OF PINEAPPLE 'PÉROLA' CULTIVAR IN TANGARÁ DA SERRA - MT, BRAZIL}

\begin{abstract}
The estimation of the cost of production for the region of study is of great importance, as it will help in the improvement of the information about the culture, that later will be able to help the familiar farmers of the region in the implantation and conduction of the culture, thus complementing its family income. The objective of this case study is to estimate the cost of production and profitability of the pineapple crop, Pérola cultivar, in Tangará da Serra, Mato Grosso. The methodology used in the work is defined by Matsunaga et al. (1976), and described by Martin et al. (1998), where the effective operational cost
\end{abstract}


(EOC) was determined, total operating cost (TOC), gross revenue (GR), operating profit $(\mathrm{OP})$, profitability index (PI), productivity and equilibrium price. The amounts referring to EOC and TOC correspond respectively to $\mathrm{R} \$ 19.313,70$ and $\mathrm{R} \$ 20.279,39$. The costs of fertilization $(27.99 \%)$, acquisition of seedlings $(25.89 \%)$, cultural treatment $(11.90 \%)$ and harvest $(9.86 \%)$ were the highest costs observed in pineapple production. For effective marketing, the OP of pineapple production was $\mathrm{R} \$ 19,480.61$, with gross revenue of $\mathrm{R} \$ 39,760.00$, profitability ratio of $49.00 \%$ and gross margin of $96.06 \%$, confirming the profitability of the activity in the region.

Key words: Ananas comosus (L.) Merril. Commercialization. Profitability.

\section{INTRODUÇÃO}

O abacaxizeiro (Ananas comosus (L.) Merril) pertence à família Bromeliaceae, fruto de regiões tropicais e subtropicais, pode ser consumido tanto in natura quanto na forma de produtos industrializados, sendo de grande importância econômica e socioeconômica (CRESTANI et al., 2010). Cultura de origem da América do Sul, das regiões Sul e Sudeste do Brasil, Uruguai e Argentina (MELO et al., 2004), o abacaxizeiro é uma planta semiperene, com ciclo variando de 14 a 24 meses, sendo que as condições climáticas, época de plantio, tipo de muda e práticas de manejo podem afetar o seu ciclo, apresentando basicamente dois períodos, um de formação ou improdutivo e outro de produção, produzindo somente um fruto por planta (PONCIANO et al., 2006).

O Brasil é considerado na América do Sul o maior produtor de abacaxi e está entre os três maiores produtores de abacaxi no mundo, com área plantada de 70.259 hectares e produção de 1.704.403 de toneladas em 2017, com um rendimento médio de 24.259 frutos por hectare e gerando 4 milhões de empregos diretos e indiretos (INSTITUTO BRASILEIRO DE GEOGRAFIA E ESTATÍSTICA - IBGE, 2017a). O estado de Mato Grosso no ranking nacional corresponde a $13^{\circ}$ posição, com uma área cultivada de 1.376 hectares, representando $1,96 \%$ da produção brasileira, com produtividade média de 22.978 frutos por hectare e produção de 31.544 toneladas (IBGE, 2017a).

Apesar do Mato Grosso estar distante dos maiores estados brasileiros produtores de abacaxi, suas condições edafoclimáticas são excelentes para a fruticultura, que notadamente oferecem condições à fruta obter boa produção, coloração e flavor (CRESTANI et al., 2010). Fatores climáticos e tipo de solo são fatores que podem influenciar na produção de culturas agrícolas como o abacaxi, e por isso dá importância de se conhecer essas variáveis para cada região de cultivo, para que o agricultor possa aprimorar o manejo de sua produção (AMBROSINI; OLIVEIRA; FAVRETO, 2017).

Segundo dados do IBGE (2017b), dentro do estado de Mato Grosso em 2017, o município de Tangará da Serra foi um dos maiores produtores do estado, demostrando-se uma forte expansão na produção de abacaxi, sendo que a cultura já ocupa uma área de 115 hectares, produzindo 4.025 toneladas, com uma produção média de $35.000 \mathrm{~kg} \mathrm{ha}^{-1}$. Referente ao plantio de abacaxi em Tangará da Serra, praticamente $90 \%$ das áreas são da cultivar Pérola, produzido principalmente por agricultores familiares. 
A pouca quantidade de informações existentes sobre a tecnologia de produção do cultivo do abacaxizeiro torna-se mais grave ainda quando se observam limitações com referência aos custos das atividades, tendo uma escassez de dados referentes a custos das práticas culturais envolvidas, desde o plantio até a colheita do produto. O conhecimento do custo operacional total (COT) torna-se necessário para conhecer ainda a participação relativa dos itens do custo operacional efetivo (COE), como forma de detalhar a remuneração atribuída a outros fatores de produção importantes, sem os quais, o cálculo da lucratividade fica prejudicado (SOUZA; COUTINHO; TORRES, 2010).

Para determinar o custo de produção de uma determinada cultura, é necessário conhecer os coeficientes técnicos de produção da mesma, sendo eles, as quantidades de insumos consumidas por hectare da cultura, expressas em tonelada, quilograma ou litro (corretivos, fertilizantes, mudas e defensivos), em horas (máquinas e equipamentos) e em dia de trabalho (PONCIANO et al., 2006).

Sabe-se que na atividade agrícola cada tomada de decisão influencia diretamente no custo de produção, visto que este é parte essencial para a gestão de qualquer atividade no meio rural (COMPANHIA NACIONAL DE ABASTECIMENTO - CONAB, 2010). Takagui, Tarsitano e Boliani (1996), em estudos com custo de produção numa lavoura de abacaxi em sequeiro, destacam a necessidade de planejar os investimentos a serem realizados.

Atualmente com o aumento da competitividade no setor agrícola, cresce também a demanda por pesquisas relacionadas sobre custos de produção (BENFICA et al., 2011; REIS et al., 2012), que para os produtores de abacaxi, um dos principais impactos positivos na agricultura está relacionado ao aumento da renda.

Sendo assim, a análise e o conhecimento dos custos de produção são fatores essenciais para o efetivo controle da produção na propriedade rural, contribuindo com informações para à otimização do uso dos recursos afim de incrementar os resultados econômicos da atividade agrícola (GALEANO; VENTURA, 2018).

Neste contexto, este estudo de caso teve como objetivo realizar a estimativa de custos totais de produção e a lucratividade da cultura do abacaxi, cultivar Pérola, no município de Tangará da Serra, Mato Grosso.

\section{MATERIAL E MÉTODOS}

O município de Tangará da Serra é distante 240 quilômetros da capital do estado de Mato Grosso, Cuiabá, possuindo área territorial de $11.597,702 \mathrm{~km}^{2}$, estando localizado nas coordenadas geográficas $14^{\circ} 37^{\prime} 40^{\prime \prime} \mathrm{S}, 57^{\circ} 30^{\prime} 25^{\prime \prime} \mathrm{W}$, com altitude de $382 \mathrm{~m}$, possuindo uma população estimada em 103.750 habitantes (IBGE, 2019), e conta com aproximadamente 2.000 estabelecimentos rurais, como descrito em Rambo (2016) (Figura 1).

De acordo com Köppen, o clima da região é classificado como tropical úmido megatérmico (AW), onde apresenta uma estação seca, que compreende os meses de maio a setembro, e uma chuvosa que vai de outubro a abril, apresentando pluviosidade média anual de $1.830 \mathrm{~mm}$ e temperatura média do ar $26,1^{\circ} \mathrm{C}$ (DALLACORT et al., 2011), sendo o solo 
predominante na região classificado como Latossolo Vermelho distroférrico com textura muito argilosa (EMPRESA BRASILEIRA DE PESQUISA AGROPECUÁRIA - EMBRAPA, 2013).

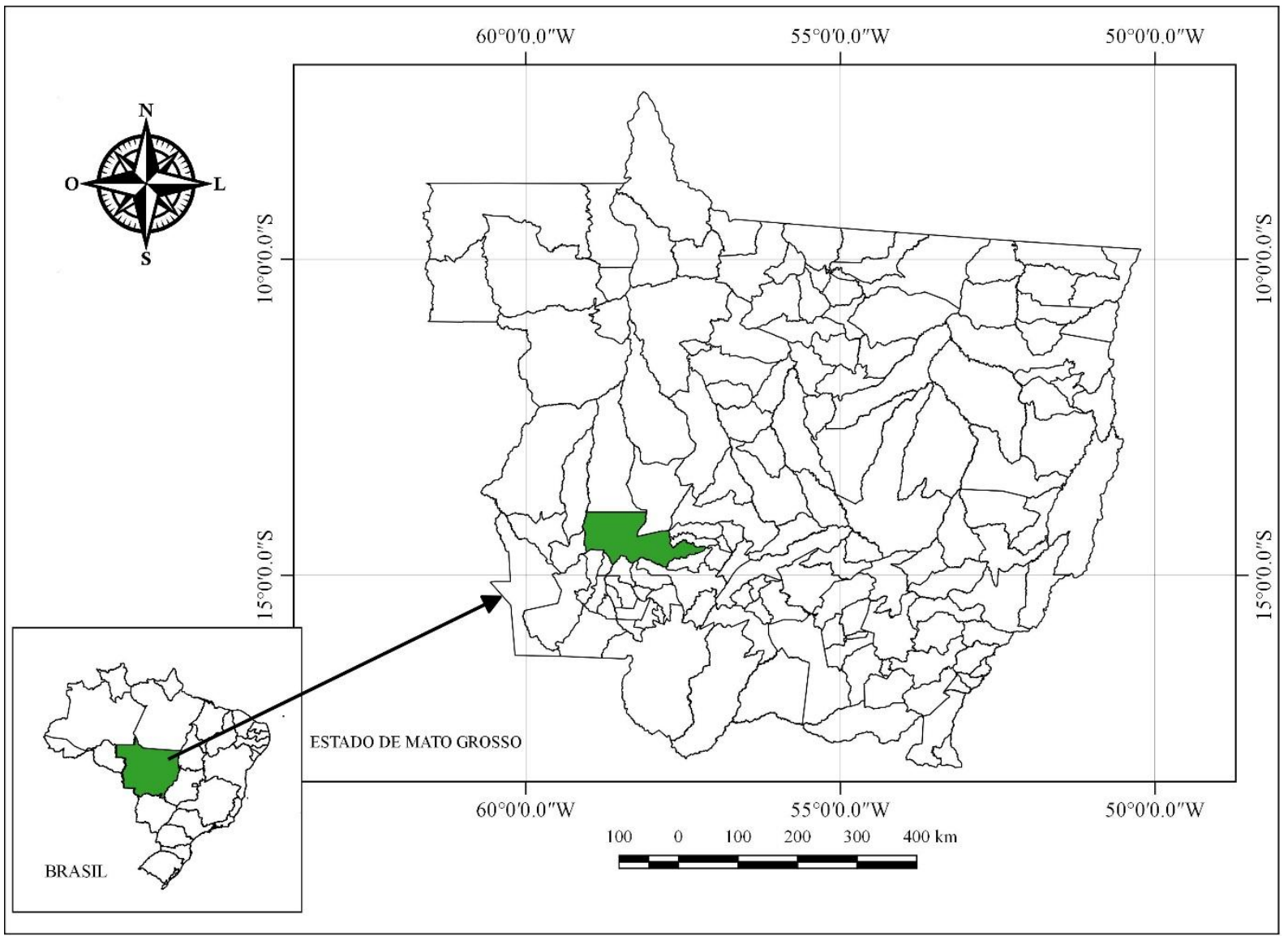

Figura 1. Localização do município de Tangará da Serra, estado de Mato Grosso, Brasil, onde está localizada a área de estudo. Location of the municipality of Tangará da Serra, Mato Grosso State, Brazil, where the study area is located.

Fonte: Autoria própria. Own authorship.

A pesquisa caracteriza-se como um estudo de caso, sendo que os dados para o respectivo estudo foram obtidos com um agricultor familiar local, em que foi realizado o levantamento do sistema de produção e a estimativa dos custos de produção e da lucratividade da cultura do abacaxizeiro para a safra 2016/2017.

Para a realização dos custos de produção, foram determinados os coeficientes técnicos da cultura do abacaxi para a região do estudo, com preços levantados em abril de 2018. Os coeficientes técnicos de produção nada mais são do que as quantidades de insumos consumidas por hectare da cultura, podendo ser expressas em tonelada, quilograma ou litro (corretivos, fertilizantes, mudas e defensivos), em horas máquina (hm) e em dia de trabalho (homem dia $=$ hd) $($ PONCIANO et al., 2006). Para o cálculo dos custos de produção utilizou um dia de trabalho com 8 horas trabalhadas $=1$ hd $=8$ horas de trabalho.

Desenvolveu-se uma análise financeira, inicialmente sendo feita a aplicação de um formulário com perguntas abertas e fechadas, conforme proposto por Rambo (2016), sendo que para as questões propostas, foram anotadas as respostas pelos entrevistadores em contato 
direto com o entrevistado, assim como descrito por Pádua (2012), obtendo assim as informações do sistema de produção da cultura estudada.

A metodologia do cálculo do custo de produção utilizada é a definida por Matsunaga et al. (1976), descrita por Martin et al. (1998), onde leva em consideração o Custo Operacional Total (COT), sendo utilizada em diversos trabalhos (LEAL et al., 2009; SOUZA; COUTINHO; TORRES, 2010; REIS et al., 2012; RAMBO et al., 2015; RAMBO, 2016; GUIMARÃES et al., 2017).

A estrutura do custo operacional total de produção da atividade foi formada pelos seguintes componentes:

a) Despesas com operações mecanizadas: são os custos com as operações agrícolas utilizadas no sistema produtivo, representados em reais com hora/máquina (hm) baseado na relação ha/hora, para a realização da roçagem, aração e gradagem da área no preparo do solo para o cultivo do abacaxi. Para o cálculo dos custos utilizou-se o valor de hora máquina de $\mathrm{R} \$ 120,00$, que é o preço médio utilizado para serviços em operações mecanizadas na região;

b) Despesas com operações manuais: foi realizado um levantamento das necessidades de mão de obra, nas diversas fases do ciclo produtivo do abacaxizeiro, relacionado, para cada operação realizada, o número de homens/dia (hd) para executá-la, sendo em seguida, multiplicado o coeficiente técnico de mão de obra pelo valor médio pago por uma diária na região ( $\mathrm{R} \$ 100,00$ a diária - 8 horas diárias de trabalho);

c) Despesas com material de consumo: os gastos com o material de consumo foram obtidos de acordo com os produtos utilizados e a quantidade dos materiais usados pelo produtor, sendo utilizado os seus respectivos preços pagos pelo produtor no mercado local;

d) Custo operacional efetivo (COE): é a soma de $\mathrm{a}+\mathrm{b}+\mathrm{c}$, representando os gastos pelo produtor para produzir um hectare de abacaxi. O produtor pode basear este custo na produção da atividade em $\mathrm{kg} \mathrm{ha}^{-1}$ e o preço unitário de venda do produto em $\left(\mathrm{R} \$ \mathrm{~kg}^{-1}\right)$;

e) Outros custos operacionais: Martin et al. (1998) propõe que os outros custos da empresa agrícola podem ser estimados sobre 5\% do COE. Outros trabalhos também citaram os custos operacionais em 5\% do COE (FACHINI et al., 2009; REIS et al., 2012; RAMBO et al., 2015; GUIMARÃES et al., 2017).

f) Custo operacional total: somatório de $d+$ e. Representa o custo operacional efetivo (COE) mais outros custos que representa $5 \%$ do COE.

Assim como em Silva et al. (2017) e Guimarães et al. (2017) não foram levados em consideração os custos de oportunidade da atividade produtiva relativos à remuneração do capital fixo em terra, instalações e máquinas, que se somados ao COT corresponderiam ao Custo Total de Produção (CTP).

Posteriormente, foi feita a análise econômica da atividade, determinando os seguintes indicadores econômicos da atividade rural, proposto por Martin et al. (1998) e empregado em diversos trabalhos (PONCIANO et al., 2006; SOUZA; COUTINHO; TORRES, 2010; ALMEIDA JÚNIOR et al., 2017; GUIMARÃES et al., 2017). 
a) Receita bruta $(\mathrm{RB})$ : receita da atividade e o respectivo rendimento por hectare, por um preço de venda médio. Receita bruta, $\mathrm{RB}=\mathrm{p} \mathrm{x} \mathrm{pv}$, onde $\mathrm{p}=$ produção da atividade $\mathrm{kg} \mathrm{ha}^{-}$ ${ }^{1} ; \mathrm{pv}=$ preço unitário de venda do produto $\left(\mathrm{R} \$ \mathrm{~kg}^{-1}\right)$;

b) Lucro operacional (LO): constituído da diferença entre os valores da receita bruta (RB) e o custo operacional total (COT) por hectare de abacaxi ( $\mathrm{LO}=\mathrm{RB}$ - COT);

c) Índice de lucratividade (IL): demonstra a relação entre o lucro operacional (LO) e a receita bruta $(\mathrm{RB})$ em percentagem $(\mathrm{IL}=(\mathrm{LO} / \mathrm{RB}) \times 100)$. Este índice demostra a taxa disponível (\%) de receita da atividade após o pagamento de todos os custos operacionais da propriedade;

d) Margem Bruta: caracteriza a disponibilidade para cobrir os demais custos fixos, o risco e a capacidade empresarial do produtor rural. Calcula-se pela relação da renda bruta pelo custo operacional total $(\mathrm{MB}=(\mathrm{RB}-\mathrm{COT}) / \mathrm{COT} \times 100))$;

e) Ponto de Nivelamento (Produção): permite visualizar, dados os custos de produção do abacaxi e o preço de venda (pv) do produto, qual a quantidade deste produto necessária para pagar os custos operacionais totais (Produção = COT/pv);

f) Ponto de Nivelamento (Preço): permite visualizar, dados os custos operacionais totais do abacaxi e a produtividade (p) do sistema produtivo, qual o preço de comercialização do abacaxi será necessário para pagar os custos de produção (Preço = COT/p).

\section{RESULTADOS E DISCUSSÃO}

O levantamento de campo para a construção da planilha de coeficientes técnicos da produção de abacaxi cultivar Pérola, efetuado na safra 2016/2017, mostrou um total de vinte e quatro operações, com finalidade de demonstrar a importância do planejamento e acompanhamento do cultivo do abacaxizeiro na região de estudo (Tabela 1).

Tabela 1. Coeficientes técnicos para produção de um hectare de abacaxi cv. Pérola em espaçamento $1,00 \times 0,40 \times 0,40 \mathrm{~m}$ (fileira dupla), em Tangará da Serra - MT. Technical coefficients for the production of one hectare of pineapple cv. Pérola in spacing $1.00 \times 0.40 \times$ 0.40 m (double row), in Tangará da Serra - MT.

\begin{tabular}{|c|c|c|}
\hline Descrição dos itens & Unidade & Especificação/Quantidade \\
\hline \multicolumn{3}{|l|}{ 1. Preparo do solo } \\
\hline Roçagem (1x) & $\mathrm{hm}^{*}$ & 2 - Trator 85 cv. $4 \times 2$ + roçadeira 1.000 r.p.m. \\
\hline Aração (1x) & $\mathrm{hm}$ & 5 - Trator $85 \mathrm{cv} .4 \times 2+$ arado fixo $4 \times 28 "$ \\
\hline Gradagem niveladora $(2 \mathrm{x})$ & $\mathrm{hm}$ & 4 - Trator $85 \mathrm{cv} .4 \times 2+$ grade niveladora $14 \times 22 "$ \\
\hline \multicolumn{3}{|l|}{ 2. Implantação da cultura } \\
\hline Mudas (filhotes) & unidade & 35.000 \\
\hline Tratamento das mudas & $\mathrm{hd}^{* *}$ & 1 \\
\hline Abertura de sulcos & hd & 2 \\
\hline Seleção/transporte/distribuição das mudas & hd & 2 \\
\hline Adubação química & hd & 2 \\
\hline Plantio e replantio & hd & 8,75 \\
\hline
\end{tabular}


Tabela 1. Continuação... Continuation...

\begin{tabular}{lcc}
\hline Descrição dos itens & Unidade & Especificação/Quantidade \\
\hline 3. Tratos culturais & & 7 \\
Pulverização defensivos (12x) & hd & 9,2 \\
Capina manual (5x) & hd & 4,6 \\
\hline Adubação de cobertura (2x) & hd & 1,33 \\
Indução floral (com repasse) & hd & 2 \\
Proteção dos frutos (1x) & hd & \\
\hline 4. Insumos & & 350 \\
Superfosfato simples (SFS) & $\mathrm{kg} \mathrm{ha}^{-1}$ & 1050 \\
Sulfato de amônia (SA) (2x) & $\mathrm{kg} \mathrm{h}^{-1}$ & 512 \\
Cloreto de potássio (KCL) (2x) & $\mathrm{kg} \mathrm{ha}^{-1}$ & 1,5 \\
Indução floral Ethrel 720 (Etefom) (2x) & $\mathrm{L} \mathrm{ha}^{-1}$ & 3,75 \\
Ureia na indução floral & $\mathrm{kg} \mathrm{ha}^{-1}$ & 1,2 \\
Inseticida Decis 25 EC (Deltametrina) (6x) & $\mathrm{L} \mathrm{ha}^{-1}$ & 1 \\
Fungicida Cercobim 700 (Tiofanato-metilico) & $\mathrm{L} \mathrm{ha}^{-1}$ & 1 \\
Fungicida Folicur 200 EC (Tebuconazol) & $\mathrm{L} \mathrm{ha}^{-1}$ & 2,5 \\
Herbicida Jump (Diurom) & $\mathrm{L} \mathrm{ha}^{-1}$ & 0,5 \\
Herbicida Magnus BR (Hexazinona) & $\mathrm{L} \mathrm{ha}$ & \\
\hline 5. Colheita & & 20 \\
Colheita manual & $\mathrm{hd}^{-1}$ & 28.000 \\
Rendimento & frutos & \\
\hline
\end{tabular}

Nota: As quantidades previstas de adubos citadas são os resultados deste estudo de caso e tem objetivo apenas de fornecer elementos para a estimativa dos custos de produção. Não foi necessário a realização de calagem, porém dependendo do caso será necessário a realização da mesma. As quantidades a serem efetivamente aplicadas de adubação e calagem dependerão de cada caso e dos resultados de análise do solo. ${ }^{*} \mathrm{hm}=$ hora máquina. *"hd = homem dia. The expected quantities of fertilizers cited are the results of this case study and are intended only to provide elements for estimating production costs. It was not necessary to perform liming, but depending on the case it will be necessary to perform it. The amounts to be effectively applied of fertilization and liming will depend on each case and the results of soil analysis. ${ }^{*} \mathrm{hm}=$ machine hour. ${ }^{* *} h d=$ man day.

Fonte: Autoria própria. Own authorship.

O espaçamento utilizado no sistema de produção estudado é de $1,00 \times 0,40 \times 0,40 \mathrm{~m}$, em fileira dupla, totalizando uma população final é de 35.000 plantas por hectare. O produtor tem perdas de $20 \%$ da produção segundo relatos do mesmo, então para o cálculo dos custos totais da produção se utilizou de uma produtividade de 28.000 frutos por hectare, sendo que cada planta produz 1 fruto por safra.

As operações mecanizadas no preparo do solo dentro da propriedade são realizadas com equipamento próprio, onde o sistema produtivo da cultura do abacaxi iniciou-se com o preparo do solo, sendo que o produtor não realizou calagem do solo, somente faz-se uma roçagem, uma aração e duas gradagens para nivelar o terreno, sendo este caracterizado como um sistema de plantio convencional. As operações mecanizadas de roçagem, aragem e gradagem consumiram duas, cinco e quatro horas máquinas por hectare, respectivamente; posteriormente foi feito a abertura dos sulcos, assim sendo a área estava preparada para receber o plantio das mudas de abacaxi.

Após o preparo da área foram feitas as operações manuais de aberturas de sulcos, seleção/transporte/distribuição das mudas e adubação química, que demandaram 2 dias de trabalho/homem cada. O agricultor familiar efetuou a adubação da cultura em plantio e 
cobertura, aplicando $350 \mathrm{~kg} \mathrm{ha}^{-1}$ de superfosfato simples, $1.050 \mathrm{~kg} \mathrm{ha}^{-1}$ de sulfato de amônia e $512 \mathrm{~kg} \mathrm{ha}^{-1}$ de cloreto de potássio por hectare nos dois tipos de adubação.

A obtenção das mudas por parte do agricultor familiar para o cultivo de um hectare de abacaxi se deu através da compra das mesmas por $\mathrm{R} \$ 0,15$ cada muda, sendo que o mesmo adquiriu 35.000 mudas por um valor de $\mathrm{R} \$ 5.250,00$. Após a aquisição das mudas, o produtor realizou o tratamento das mudas ao sol (cura), que demandou um dia de trabalho/homem por hectare para acondicionamento e organização das mudas ao sol, a fim de que se acelere a cicatrização dos tecidos lesados, elimine o excesso de água da muda, evite seu apodrecimento após o plantio e contribua para aumentar a eficiência da seleção visual quanto à sanidade (REINHARDT; CUNHA, 2006).

O plantio da cultura foi efetuado em outubro de 2016, sendo que a cultura possui um ciclo em média de 420 dias. Por isso foi estimado os custos de produção do abacaxi para o período de formação ( 8 - 10 meses) e para a produção (6 meses). As atividades de plantio e replantio demandaram 8,75 dias de trabalho/homem por hectare. Para que o plantio pudesse ser feito, o agricultor demandou de dois dias de trabalho/homem para que fosse feito a seleção, o transporte e a distribuição das mudas na área de plantio.

Foi necessária a realização de capina manual em pós plantio para o controle de plantas daninhas, que foram feitas por duas vezes em todo o ciclo da cultura e tiveram duração de 3,7 dias de trabalho/homem. Posteriormente, também se realizou uma adubação de cobertura, atividade que demandou mais 4,6 dias de trabalho/homem.

Nas atividades de tratos culturas para a cultura do abacaxi foi realizado também a indução floral artificial, com objetivo de diminuição dos custos e escalonamento da colheita do abacaxi, racionalizando o uso da mão de obra e ofertando frutos em períodos de escassez no mercado (CARVALHO et al., 2005), sendo que esta atividade demandou 1,33 dias de trabalho/homem entre a aplicação e o repasse por ventura era necessitado.

Para a proteção dos frutos, evitando a queimadura provocada pelos raios solares que deprecia o valor comercial do produto, e também tem a função de dar uniformidade na coloração dos frutos, o produtor se utilizou de capim existente na propriedade, este serviço consumiu dois dias de trabalho/homem.

O agricultor realizou o plantio de 35.000 mudas de abacaxi, porém devido a ocorrência de chuvas no período de cultivo, houve o aparecimento de algumas doenças, como por exemplo, a fusariose (Fusarium subglutinans f. sp. ananas), assim ele obteve somente 28.000 frutos por hectare, ou seja, somente $80 \%$ dos pés de abacaxi foram produtivos e geraram frutos.

Segundo Reis et al. (2012), grande parte dos produtores de abacaxi ainda tem elevadas perdas por deficiência no sistema produtivo, principalmente no controle de pragas, como a broca-do-fruto (Strymon megarus) e doenças como a fusariose, bem como deficiências no gerenciamento de custos de produção. Tudo isso são fatores importantes que podem prejudicar a produtividade e lucratividade do negócio.

A colheita foi feita diariamente de forma manual e teve duração de 20 dias de trabalho/homem. A comercialização da produção foi realizada através de dois canais, sendo 
que tinha preços diferentes entre os mesmos, associado com o tipo e a qualidade dos abacaxis ofertados, podendo citar a venda direta ao consumidor final e para atravessadores da região.

Com base nos coeficientes técnicos indicados para a cultura do abacaxi, foi possível estimar os custos de produção para 1 hectare de cultivo. A tabela com o cálculo de custo operacional total (COT) de produção da cultura, com o custo operacional efetivo (COE), com os custos de operações mecanizadas, operações manuais, materiais consumidos (insumos) e com os outros custos operacionais para a cultura, pode ser visualizada na Tabela 2.

Tabela 2. Estimativa do custo operacional total (COT) por hectare obtido na cultura do abacaxizeiro cv. Pérola, em Tangará da Serra - MT na safra de 2016/2017. Estimated total operating cost (TOC) per hectare obtained in the pineapple cv. Pérola in Tangará da Serra MT in the 2016/2017 harvest.

\begin{tabular}{|c|c|c|c|c|c|c|c|c|c|}
\hline \multirow[t]{3}{*}{ Operações } & \multirow{3}{*}{ Especificação } & \multirow{3}{*}{$\begin{array}{c}\text { Valor } \\
\text { unitário } \\
(\mathrm{R} \$)\end{array}$} & \multirow{2}{*}{\multicolumn{3}{|c|}{$\begin{array}{c}\text { Formação } \\
\text { Ano } 1\end{array}$}} & \multirow{2}{*}{\multicolumn{3}{|c|}{$\begin{array}{c}\text { Produção } \\
\text { Ano } 2\end{array}$}} & \multirow{3}{*}{$\begin{array}{c}\% \\
\text { Total }\end{array}$} \\
\hline & & & & & & & & & \\
\hline & & & $\begin{array}{c}\mathrm{N}^{\circ} \\
\text { vezes }\end{array}$ & Quant. & Valor $(\mathrm{R} \$)^{*}$ & $\begin{array}{c}\mathrm{N}^{\circ} \\
\text { vezes }\end{array}$ & Quant. & Valor $(\mathrm{R} \$)^{*}$ & \\
\hline \multicolumn{10}{|c|}{ A - Operações mecanizadas } \\
\hline \multicolumn{10}{|l|}{ A.1. Preparo do solo } \\
\hline Roçagem & $\mathrm{hm}^{* *}$ & 120,00 & 1 & 2 & 240,00 & - & - & - & 1,18 \\
\hline Aração & $\mathrm{hm}$ & 120,00 & 1 & 5 & 600,00 & - & - & - & 2,96 \\
\hline Gradagem & $\mathrm{hm}$ & 120,00 & 2 & 4 & 480,00 & - & - & - & 2,37 \\
\hline Subtotal A & & & & & $1.320,00$ & & & 0,00 & 6,51 \\
\hline \multicolumn{10}{|c|}{ B - Operações manuais } \\
\hline \multicolumn{10}{|c|}{ B.1. Implantação da cultura } \\
\hline Trat. das mudas & $\mathrm{hd}^{* * * *}$ & 100,00 & 1 & 1 & 100,00 & - & - & - & 0,49 \\
\hline Abertura sulcos & hd & 100,00 & 1 & 2 & 200,00 & - & - & - & 0,99 \\
\hline Transp./distr. mudas & hd & 100,00 & 1 & 2 & 200,00 & - & - & - & 0,99 \\
\hline Adub. química & hd & 100,00 & 1 & 2 & 200,00 & - & - & - & 0,99 \\
\hline Plantio/replantio & hd & 100,00 & 1 & 8,75 & 875,00 & - & - & - & 4,31 \\
\hline \multicolumn{10}{|l|}{ B.2. Tratos culturais } \\
\hline Pulverização & hd & 100,00 & 2 & 1,75 & 175,00 & 10 & 5,25 & 525,00 & 3,45 \\
\hline Capina manual & hd & 100,00 & 2 & 3,7 & 370,00 & 3 & 5,5 & 550,00 & 4,54 \\
\hline Adub. cobertura & hd & 100,00 & 2 & 4,6 & 460,00 & - & - & - & 2,27 \\
\hline Indução floral & hd & 100,00 & - & - & - & 1 & 0,88 & 88,00 & 0,43 \\
\hline Ind. floral repasse & hd & 100,00 & - & - & - & 1 & 0,45 & 45,00 & 0,22 \\
\hline Proteção frutos & hd & 100,00 & - & - & - & 1 & 2 & 200,00 & 0,99 \\
\hline \multicolumn{10}{|l|}{ B.3. Colheita } \\
\hline Colheita & hd & 100,00 & - & - & - & 1 & 20 & $2.000,00$ & 9,86 \\
\hline Subtotal B & & & & & $2.580,00$ & & & $3.408,00$ & 29,53 \\
\hline \multicolumn{10}{|c|}{ C - Despesas com material de consumo - Insumos } \\
\hline \multicolumn{10}{|c|}{ C.1. Fertilizantes (plantio e cobertura) ${ }^{* * * * *}$} \\
\hline SFS & $\mathrm{R} \$ \mathrm{~kg}^{-1}$ & 3,33 & 1 & 350 & $1.165,50$ & - & - & - & 5,75 \\
\hline SA & $\mathrm{R} \$ \mathrm{~kg}^{-1}$ & 3,33 & 2 & 1050 & $3.496,50$ & - & - & - & 17,24 \\
\hline KCL & $\mathrm{R} \$ \mathrm{~kg}^{-1}$ & 1,98 & 2 & 512 & $1.013,76$ & - & - & - & 5,00 \\
\hline \multicolumn{10}{|l|}{ C.2. Fitossanitários } \\
\hline \multicolumn{10}{|l|}{ C.2.1. Indução floral } \\
\hline Indução floral & $\mathrm{R} \$ \mathrm{~L}^{-1}$ & 280,00 & - & - & - & 2 & 1,5 & 420,00 & 2,07 \\
\hline Ureia & $\mathrm{R} \$ \mathrm{~kg}^{-1}$ & 2,00 & - & - & - & 2 & 3,75 & 7,50 & 0,04 \\
\hline
\end{tabular}


Tabela 2. Continuação... Continuation...

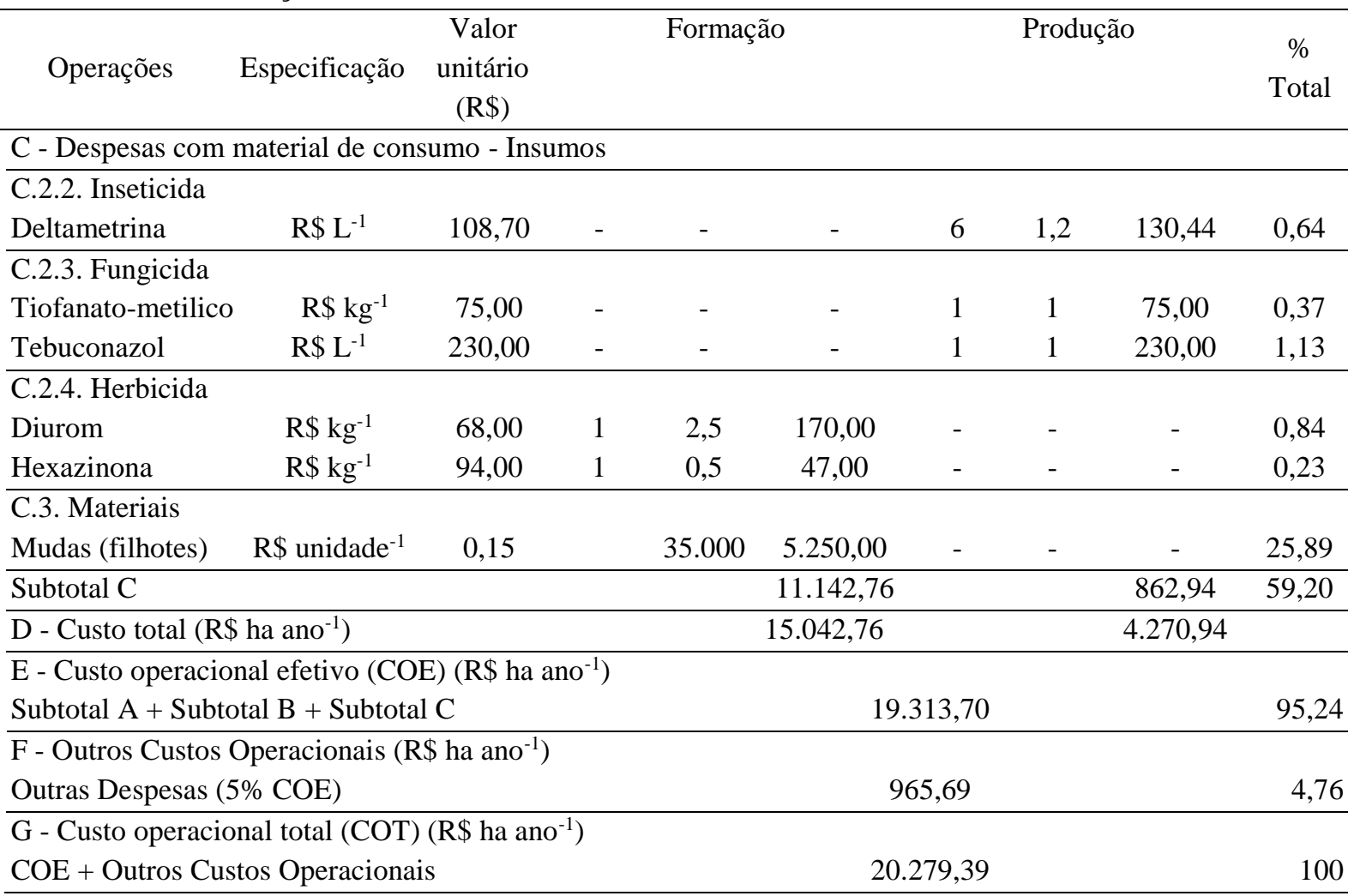

Nota: *Este valor já computa a quantidade correspondente de vezes que aquela determinada operação foi feita. ${ }^{* * *} \mathrm{hm}=$ hora máquina. ${ }^{* * *}$ hd = homem dia. Obs: ${ }^{* * * *}$ Em função da análise de solo. SFS = Super Fosfato Simples. $\mathrm{SA}=$ Sulfato de Amônia. $\mathrm{KCL}=$ Cloreto de Potássio. Note: ${ }^{*}$ This value already computes the corresponding number of times that given operation was performed. ${ }^{* *} h m=$ machine time. ${ }^{* * *} h d=$ man day. Note: ${ }^{* * * * *}$ Depending on the soil analysis. $S F S=$ Simple Super Phosphate. $S A=$ Ammonium Sulfate. $K C L=$ Potassium Chloride.

Fonte: Autoria própria. Own authorship.

As despesas com operações mecanizadas da cultura do abacaxi foram de $\mathrm{R} \$ 1.320,00$ por hectare, representando 6,51\% do COT da atividade. Já as despesas com roçagem, aração e gradagem da área corresponderam a $\mathrm{R} \$ 240,00(18,18 \%), \mathrm{R} \$ 600,00(45,45 \%)$ e $\mathrm{R} \$ 480,00$ $(36,37 \%)$ das despesas com operações mecanizadas, respectivamente.

Atividades de preparo do solo tem grande importância na produção do abacaxizeiro, de maneira que a realização de plantio convencional do abacaxi promove um aumento na produção, provavelmente por deixar o solo com condições favoráveis ao crescimento de raízes e auxiliando no estabelecimento inicial das mudas (MODEL; SANDER, 1999).

As despesas com operações manuais, custaram $\mathrm{R} \$ 2.580,00$ na fase de formação e $\mathrm{R} \$ 3.408,00$ na fase de produção, custos estes para um hectare. Estes representam 29,53\% do COT.

As despesas com operações manuais demandam um alto investimento, pois geram maiores custos nas atividades de plantio, na capina manual e na colheita, no valor de $\mathrm{R} \$ 875,00$ (4,31\% do COT), $\mathrm{R} \$ 920,00$ (4,54\% do COT) e $\mathrm{R} \$ 2.000,00$ (9,86\% do COT), respectivamente.

Reis et al. (2012) encontraram custos com operações manuais com valores percentuais 
de $11,77 \%$ (formação) e 45,22 \% (produção), do custo operacional total (COT). Culturas de ciclo mais longo, como o abacaxizeiro, os custos de produção podem ser avaliados por período, assim o produtor saberá em qual época da produção demandará um maior investimento na cultura.

Leal et al. (2009) analisando a viabilidade econômica de cultivo do abacaxizeiro no arenito Caiuá, no estado do Paraná, descreveram que as operações manuais são responsáveis por $23,55 \%$ do COT. Guimarães et al. (2017), estudando os custo de produção para a mesma região de estudo, verificaram despesas com operações manuais correspondendo a 74,02\% do COT, muito acima dos $29,53 \%$ deste estudo. Diferença esta que pode ser explicada pelos diferentes sistemas de produção utilizados nestes estudos, demostrando assim a variabilidade dentro de uma mesma região, dependendo do sistema utilizado pelo agricultor.

As despesas com os materiais consumidos, entre eles: fertilizantes, fitossanitários, e outros materiais (mudas) foram de $\mathrm{R} \$ 12.005,70$ por hectare e representaram 59,20\% do COT, sendo essa a maior fonte de gastos com a produção de abacaxi na região. Os fertilizantes foram responsáveis por $\mathrm{R} \$ 5.675,76$ representando 27,99\% do COT, os fitossanitários tiveram custo de $\mathrm{R} \$ 1.079,94(5,32 \%$ do COT) e a mudas com valor de $\mathrm{R} \$ 5.250,00$ (25,89\% do COT).

Para este estudo de caso, pode-se observar que os fertilizantes e a aquisição de mudas foram os que mais demandaram custos na produção de abacaxi. Reis et al. (2012) descrevem os custos com fertilizantes um dos custos mais onerosos da produção, e Reinhardt (2004) o custo das mudas, é um dos maiores custos envolvidos na produção do abacaxi. Leal et al. (2009) traz como custos das mudas um percentual de 22,76\% do COT e Galeano e Ventura (2018) descrevem $\mathrm{R} \$ 5.201,13$, ou seja, um percentual de 24,8\% do COT como custo com aquisição de mudas da cultivar Pérola, valores semelhantes aos encontrados neste estudo.

A partir da próxima safra, a ser realizada pelo produtor em sua propriedade, o mesmo poderá reduzir seu custo de produção em razão de não necessitar realizar uma nova compra de mudas, poderá obter as suas mudas de seu cultivo anterior, através da seleção das mesmas para a formação de um novo plantio. Sendo esta uma prática comum na região, quando de cultivos do segmento da agricultura familiar, conforme mostram Rambo et al. (2015) e Guimarães et al. (2017).

O custo operacional efetivo (COE) é de $\mathrm{R} \$ 19.313,70$ (95,24\% do COT), representando a somas das despesas com operações mecanizadas, manuais e com insumos. Isto representa os gastos reais que o produtor teve para produzir um hectare de abacaxi. Outras despesas (5\% do $\mathrm{COE}$ ) foram de $\mathrm{R} \$ 965,69$, representando $4,76 \%$ do COT, que corresponde à parte das despesas gerais da propriedade, com a finalidade de aumentar a precisão na avaliação dos custos e indicadores econômicos da produção.

Observando o custo operacional total (COT), encontrado no valor de $\mathrm{R} \$ 20.279,39$, semelhante ao valor encontrado por Galeano e Ventura (2018), que trazem como COT para cultivar Pérola um valor de $\mathrm{R} \$ 20.982,36$ e quando estudaram outras cultivares este valor aumentou, sendo R $\$ 23.917,71$ (cultivar Vitória) e R $\$ 28.221,43$ (cultivar Smooth Cayenne), observando assim que até mesmo entre cultivares de abacaxi o COT sofre variações. 
Com relação as estimativas de produção, preços para as diferentes formas de comercialização e indicadores os financeiros, tais como: lucro operacional (LO), índice de lucratividade (IL), margem bruta (MB), ponto de nivelamento (PN) (frutos ha ${ }^{-1}$ e R $\$$ fruto $^{-1}$ ) para a cultura do abacaxi, podem ser visualizadas na Tabela 3.

$\mathrm{Na}$ comercialização do abacaxi, a receita bruta do agricultor familiar, como se observa, pode variar de $\mathrm{R} \$ 28.000,00$ a $\mathrm{R} \$ 56.000,00$, diferença a ser justificada pelo tipo de venda que foi realizada pelo produtor, onde que o preço do nivelamento da produção ( $\mathrm{R} \$ 0,72)$, não varia independentemente do tipo de venda exercida. Galeano e Ventura (2018), verificaram para a cultivar Pérola uma receita bruta no valor de $\mathrm{R} \$ 22.173,74$, do mesmo modo Leal et al. (2009) encontraram valores de receita bruta de $\mathrm{R} \$ 18.739,40$ para venda dos frutos na lavoura e de $\mathrm{R} \$ 25.820,00$ para frutos vendidos direto ao consumidor.

Tabela 3. Estimativas de produção, preços e indicadores financeiros para um hectare, da cultura do abacaxi cv. Pérola, em Tangará da Serra - MT na safra de 2016/2017. Estimates of production, prices and financial indicators for one hectare, of pineapple cv. Pérola, in Tangará da Serra - MT in the 2016/2017 harvest.

\begin{tabular}{|c|c|c|c|c|}
\hline Indicadores financeiros & $\begin{array}{l}\text { Venda } \\
\text { direta }\end{array}$ & $\begin{array}{l}\text { Atravessadores } \\
\text { (frutos maiores) }\end{array}$ & $\begin{array}{l}\text { Atravessadores } \\
\text { (frutos menores) }\end{array}$ & $\begin{array}{c}\text { Ponderada } \\
(7,14 \%-37,50 \%- \\
55,36 \%)\end{array}$ \\
\hline Preço Médio $\left(\mathrm{R} \$\right.$ fruto $\left.^{-1}\right)$ & 1,60 & 2,00 & 1,00 & 1,42 \\
\hline Produtividade (frutos ha ${ }^{-1}$ ) & 28.000 & 28.000 & 28.000 & 28.000 \\
\hline Receita Bruta $\left(\mathrm{R} \$\right.$ ha $\left.^{-1}\right)$ & $44.800,00$ & $56.000,00$ & $28.000,00$ & $39.760,00$ \\
\hline $\operatorname{COT}\left(\mathrm{R} \$ \mathrm{ha}^{-1}\right)$ & $20.279,39$ & $20.279,39$ & $20.279,39$ & $20.279,39$ \\
\hline Lucro Operacional (LO) $\left(\mathrm{R} \$ \mathrm{ha}^{-1}\right)$ & $24.520,61$ & $35.720,61$ & $7.720,61$ & $19.480,61$ \\
\hline Índice de Lucratividade (IL) (\%) & 54,73 & 63,79 & 27,57 & 49,00 \\
\hline Margem Bruta (\%) & 120,91 & 176,14 & 38,07 & 96,06 \\
\hline Ponto de Nivelamento (frutos ha ${ }^{-1}$ ) & 12.675 & 10.140 & 20.279 & 14.281 \\
\hline Ponto de Nivelamento $\left(\mathrm{R} \$\right.$ fruto $\left.^{-1}\right)$ & 0,72 & 0,72 & 0,72 & 0,72 \\
\hline
\end{tabular}

Fonte: Autoria própria. Own authorship.

A venda direta ${ }^{1}$ ao consumidor final, onde o agricultor ofertava seus frutos de casa em casa, a fim de comercializa-los, recebendo mais por frutos maiores e um pouco menos por frutos menores, com isso foi determinado o preço de venda média para este tipo de comercialização que foi de $\mathrm{R} \$ 1,60$. Se toda a produção fosse vendida por este preço, a receita bruta seria de $\mathrm{R} \$ 44.800,00$. O lucro operacional seria de $\mathrm{R} \$ 24.520,61$, e com índice de lucratividade de $54,73 \%$.

A venda para atravessadores se dava diretamente em sua propriedade, em que o agricultor vendia seus frutos de maneira direta para feirantes, que posteriormente iriam comercializar os frutos na feira do produtor de Tangará da Serra - MT e também para pessoas de outros municípios ao entorno que vinham até a propriedade para comprar a sua produção. Dentre as comercializações do produtor para atravessadores, ele recebeu $\mathrm{R} \$ 2,00$ por frutos maiores e $\mathrm{R} \$ 1,00$ por frutos menores.

$\mathrm{Na}$ venda para os atravessadores dos frutos maiores e com mais qualidade ( $\mathrm{R} \$ 2,00$ por fruto), se toda a venda fosse feita a este valor, se obteria uma receita bruta de $\mathrm{R} \$ 56.000,00$. O

\footnotetext{
${ }^{1}$ Venda direta: Porta a porta (door to door): modalidade tradicional praticada pelo produtor em estudo, onde nela o agricultor vai à casa ou ao local de trabalho do consumidor final para comercializar a sua produção.
} 
lucro operacional da atividade seria, então, de $\mathrm{R} \$ 35.720,61$, visto que o produtor obteve um saldo positivo com a implantação dessa cultura durante a safra, o que demonstra ser a atividade lucrativa no curto prazo. $\mathrm{O}$ índice de lucratividade foi de $63,79 \%$, sendo que o produtor teria de receita, após o pagamento de todas as despesas.

Já para a venda para os atravessadores dos frutos menores e com menos qualidade ( $\mathrm{R} \$ 1,00$ por fruto), com toda a produção vendida por este preço, o produtor teria uma receita bruta de $\mathrm{R} \$ 28.000,00$, com lucro operacional de $\mathrm{R} \$ 7.720,61$ e com índice de lucratividade de $27,57 \%$.

Quando leva-se em conta a comercialização efetiva do produtor (comercialização ponderada), ou seja, 2.000 frutos de abacaxi foram vendidos pelo produtor a $\mathrm{R} \$ 1,60$ ( $\mathrm{R} \$ 3.200,00$ - 7,14\% da produção), 10.500 frutos foram comercializados a $\mathrm{R} \$ 2,00$ ( $\mathrm{R} \$ 21.000,00$ - 37,50\% da produção) e 15.500 frutos foram vendidos por $\mathrm{R} \$ 1,00$ ( $\mathrm{R} \$ 15.500,00$ - 55,36\% da produção), assim pode-se calcular o preço de venda ponderado $(7,14 \%-37,50 \%-55,36 \%)$, onde a receita bruta neste tipo de venda $(\mathrm{R} \$ 39.760,00)$ em relação da produtividade (28.000 frutos), resultou nesta modalidade, um preço de $\mathrm{R} \$ 1,42$ por fruto vendido.

Para este tipo de venda feita pelo agricultor familiar, a receita bruta foi de $\mathrm{R} \$ 39.760,00$, lucro operacional de $\mathrm{R} \$ 19.480,61$, índice de lucratividade de 49,00\%, sendo assim os preços obtidos com esse tipo de venda apresentam renda líquida positiva para a atividade e poderá remunerar outros custos não incluídos nesse cálculo.

Quando analisa-se a margem bruta, observam-se valores para venda direta $(120,91 \%)$, atravessadores (176,14\% para frutos maiores e 38,07\% para frutos menores) e para comercialização ponderada $(96,06 \%)$ de todo o COT. Havendo possibilidade de remuneração do risco e da capacidade empresarial deste produtor.

Em relação ao ponto de nivelamento (produção) o produtor terá que produzir para a venda direta (12.675 frutos), atravessadores (10.140 para frutos maiores e 20.279 para frutos menores) e para comercialização ponderada (14.281 frutos) para cobrir seu custo de produção, sendo que produziu para um hectare um total de 28.000 frutos, ultrapassando a produção mínima necessária para cobrir os seus custos.

Em vista disso, pode-se concluir que o produtor obteve lucro na sua produção, devido ao COT ser somente $51,00 \%$ da receita bruta total na média ponderada, sendo assim, com a orientação correta e utilizando todas as práticas corretas de manejo se apresenta rentável, justificando assim a continuidade do produtor nesta atividade.

A cultura do abacaxi possui elevado potencial de expressão econômica e social, uma vez que problemas relacionados à produtividade e ao gerenciamento dos custos de produção sejam solucionados de maneira a garantir a sustentabilidade do sistema de cultivo (REIS et al., 2012). Tecnologias geradas nas instituições de pesquisa estão sendo recomendadas sem uma análise mais precisa da relação benefício/custo. Produzir mais, com melhor qualidade e menor custo operacional, significa melhorar as condições de competitividade e garantir maior retorno econômico (SOUZA; COUTINHO; TORRES, 2010).

Conhecer os custos de produção da cultura do abacaxi, a receita gerada pela cultura e o 
ponto de equilíbrio são dados importantes para verificar a viabilidade econômica para quem quer iniciar a exploração econômica dessa cultura (MIAKE; BORGHI; MARTINS, 2011). Realizar a contabilização dos custos de produção de uma propriedade garante que o produtor saiba se sua propriedade e suas atividades agrícolas estão sendo viáveis ou não, como demonstrado nesse trabalho a partir das coletas de dados que está sendo viável, pois o seu índice de lucratividade ponderado de $49,00 \%$ está suprindo todos os custos que o produtor tem na sua produção.

Outro fator importante que pode agregar valor na produção de abacaxi é a utilização de sistema de irrigação, de modo que alguns autores citam que a utilização de irrigação para suplementar a falta de chuvas em certos períodos do ano podem incrementar a produção da cultura (MELO et al., 2006; SOUZA; SILVA; AZEVEDO, 2007), porém a rentabilidade do plantios iniciais da cultura pode diminuir com gastos de aquisição, manutenção e depreciação dos equipamentos de irrigação, sendo que custo como estes podem representar até $50 \%$ do custo total de produção (PONCIANO et al., 2006).

\section{CONCLUSÃO}

O cultivo de abacaxizeiro cv. Pérola demonstrou possuir um elevado potencial de expressão econômica para os agricultores familiares do município de Tangará da Serra - MT, uma vez que pode remunerar a mão de obra familiar da região.

Os custos com a adubação (27,99\%), aquisição de mudas (25,89\%), tratos culturais $(11,90 \%)$ e colheita $(9,86 \%)$ foram os maiores gastos observados na produção do abacaxi.

A média de produtividade, bem como os principais parâmetros de rentabilidade ponderados (lucro operacional, índice de lucratividade e margem bruta) se mostraram rentáveis ao produtor, de maneira que o mesmo está tendo lucro com sua produção de abacaxi.

\section{REFERÊNCIAS BIBLIOGRÁFICAS}

ALMEIDA JÚNIOR, J. J.; SANTOS, G. A.; PEROZINE, A. C.; MATOS, F. S. A.; SMILJANIC, K. B. A.; MARTINS FILHO, M. B. Custo de implantação da cultura da mandioca (Manihot esculenta L.), no sudoeste goiano, município de Mineiros estado de Goiás. In: COLÓQUIO ESTADUAL DE PESQUISA MULTIDISCIPLINAR, 2017, Mineiros. Anais [...] Mineiros: UNIFIMES, 2017, p. 1-14. Disponível em: www.unifimes.edu.br/ojs/index.php/coloquio/article/view/23. Acesso em: 12 maio 2019.

AMBROSINI, L.; OLIVEIRA, C.; FAVRETO, R. Evolução dos sistemas agrários no território de produção do "abacaxi terra de areia" no litoral do Rio Grande do Sul. Desenvolvimento Regional em Debate, Canoinhas, v. 7, n. 1, p.25-50, 2017. Disponível em: http://www.periodicos.unc.br/index.php/drd/article/view/1303. Acesso em: 04 abr. 2019.

BENFICA, A. F.; OLIVEIRA, A. M. G.; CARDOSO, C. E. L.; JUNGHANS, D. T.; REINHARDT, D. H. R. C.; CUNHA, G. A. P.; JESUS, G. S.; OLIVEIRA, J. L.; CABRAL, J. R. S.; SOUZA, L. F. S.; SANCHES, N. F. Sistema de produção de abacaxi para o extremo 
sul da Bahia. Cruz das Almas: Embrapa Mandioca e Fruticultura, 2011. 63 p.

CARVALHO, S. L. C.; NEVES; C. S. V. J.; BÜRKLE, R.; MARUR, C. J. Floral induction period and thermal time requirements from the flowering to the harvest period for Smooth Cayenne pineapple. Revista Brasileira de Fruticultura, Jaboticabal, v. 27, n. 3, p.430-433, 2005. Disponível em: http://www.scielo.br/pdf/rbf/v27n3/27790.pdf. Acesso em: 15 abr. 2019.

COMPANHIA NACIONAL DE ABASTECIMENTO - CONAB. Custos de produção agrícola: a metodologia da Conab. Brasília, DF, 2010. Disponível em: http://www.conab.gov.br/conabweb/download/safra/custos.pdf. Acesso em: 05 jan. 2019.

CRESTANI, M.; BARBIERI, R. L.; HAWERROTH, F. J.; DE CARVALHO, F. I. F.; OLIVEIRA, A. C. From the Americas to the World - origin, domestication and dispersion of pineapple. Ciência Rural, Santa Maria, v. 40, n. 6, p.1473-1483, 2010. Disponível em: http://www.scielo.br/pdf/cr/v40n6/a620cr2584.pdf. Acesso em: 15 abr. 2019.

DALLACORT, R.; MARTINS, J. A.; INOUE, M. H.; FREITAS, P. S. L. de; COLETTI, A. J. Distribuição das chuvas no município de Tangará da Serra, médio norte do Estado de Mato Grosso, Brasil. Acta Scientiarum. Agronomy, Maringá, v. 33, n. 2, p.193-200, 2011. Disponível em: http://www.scielo.br/pdf/asagr/v33n2/01.pdf. Acesso em: 04 jan. 2019.

EMPRESA BRASILEIRA DE PESQUISA AGROPECUÁRIA - EMBRAPA. Sistema brasileiro de classificação dos solos. 3. ed. Brasília: EMBRAPA Solos, 2013. 353 p.

FACHINI, C.; RAMOS JUNIOR, E. U.; BARROS, V. L. N. P.; LUCHESI JUNIOR, V. Viabilidade econômica das culturas de feijão, abóbora e mandioca para indústria em consórcio com eucalipto, região de Capão Bonito, estado de São Paulo. Informações Econômicas, São Paulo, v. 39, n. 5, p.16-28, 2009. Disponível em: http://www.iea.sp.gov.br/ftpiea/publicacoes/IE/2009/tec2-0509.pdf. Acesso em: 19 abr. 2019.

GALEANO, E. A. V.; VENTURA, J. A. Análise comparativa de custos de produção e avaliação econômica dos abacaxis 'Vitória', 'Pérola' e 'Smooth Cayenne'. Revista de Ciências Agrárias, Belém, v. 61, n. 1, p.1-7, 2018. Disponível em: https://ajaes.ufra.edu.br/index.php/ajaes/article/view/2765. Acesso em: 02 abr. 2019.

GUIMARÃES, H. A.; RAMBO, J. R.; LAFORGA, G.; SANTOS, P. R. J. Análise econômica e custo de produção de abacaxi: estudo de caso em Tangará da Serra, Estado de Mato Grosso, 2016. Informações Econômicas, São Paulo, v. 47, n. 4, p.41-50, 2017. Disponível em: http://www.iea.sp.gov.br/ftpiea/ie/2017/tec4-1017.pdf. Acesso em: 09 jan. 2019.

INSTITUTO BRASILEIRO DE GEOGRAFIA E ESTATÍSTICA - IBGE. Cidades. Brasília, DF, 2019. Disponível em: https://cidades.ibge.gov.br/brasil/mt/tangara-da-serra/panorama. Acesso em: 03 out. 2019.

INSTITUTO BRASILEIRO DE GEOGRAFIA E ESTATÍSTICA - IBGE. Levantamento sistemático da produção agrícola. Pesquisa mensal de previsão e acompanhamento das safras agrícolas no ano civil. Brasília: IBGE, 2017a. Disponível em: https://biblioteca.ibge.gov.br/visualizacao/periodicos/6/lspa_pesq_2017_dez.pdf. Acesso em: 27 mar. 2019. 
INSTITUTO BRASILEIRO DE GEOGRAFIA E ESTATÍSTICA - IBGE. SIDRA: Sistema IBGE de Recuperação Automática: Produção Agrícola Municipal. Brasília: IBGE, 2017b. Disponível em: https://biblioteca.ibge.gov.br/index.php/bibliotecacatalogo?view=detalhes\&id=298009. Acesso em: 01 mar. 2019.

LEAL, A. J. F.; HORA, R. C.; TONIN, T. A.; BOLIANI, A. C. Viabilidade econômica do cultivo de abacaxi no arenito Caiuá, região noroeste do Paraná. Acta Scientiarum. Agronomy, Maringá, v. 31, n. 2, p.353-358, 2009. Disponível em: http://periodicos.uem.br/ojs/index.php/ActaSciAgron/article/view/7041. Acesso em: 22 fev. 2019.

MARTIN, N. B.; SERRA, R.; OLIVEIRA, M. D. M.; ÂNGELO, J. A.; OKAWA, H. Sistema integrado de custos agropecuários - CUSTAGRI. Informações Econômicas, São Paulo, v. 28, n. 1, p.7-28, 1998. Disponível em: http://www.iea.sp.gov.br/ftpiea/ie/1998/tec1-0198.pdf. Acesso em: 22 out. 2018.

MATSUNAGA, M.; BEMELMANS, P. F.; TOLEDO, P. E. N.; DULLEY, R. D.; OKAWA, H.; PEDROSO, I. A. Metodologia de custo de produção utilizada pelo IEA. Agricultura em São Paulo, São Paulo, v. 23, n. 1, p.123-139, 1976. Disponível em: http://www.iea.sp.gov.br/out/verTexto.php?codTexto=11566. Acesso em: 22 out. 2018.

MELO, A. S.; AGUIAR NETTO, A. O.; DANTAS NETO, J.; BRITO, M. E. B.; VIÉGAS, P. R. A.; MAGAlHÃES, L. T. S.; FERNANDES, P. D. Desenvolvimento vegetativo, rendimento da fruta e otimização do abacaxizeiro cv. Pérola em diferentes níveis de irrigação.

Revista Ciência Rural, Santa Maria, v. 36, n. 1, p.93-98, 2006. Disponível em: http://www.scielo.br/pdf/cr/v36n1/a14v36n1.pdf. Acesso em: 12 fev. 2019.

MELO, A. S.; VIÉGAS, P. R. A.; MELO, D. L. M. F.; COSTA, L. A. S.; GÓIS, M. P. P. Rendimento, qualidade da fruta e lucratividade do abacaxizeiro cv. Pérola em diferentes espaçamentos. Revista de Ciências Agrárias, Belém, v. 41, n. 1, p.185-192, 2004. Disponível em: https://periodicos.ufra.edu.br/index.php/ajaes/article/view/2386. Acesso em: 25 fev. 2019.

MIAKE, H.; BORGHI, W. A.; MARTINS, E. T. Custo de produção da cultura do abacaxi na chácara duas meninas em Santa Isabel do Ivaí - PR. In: CONGRESSO REGIONAL DE ADMINISTRAÇÃO, 1, 2011, Loanda. Anais [...] Loanda: FACINOR, 2011. p. 1-15.

MODEL, N. S.; SANDER, G. R. Produtividade e características do fruto de abacaxizeiro em função do preparo do solo e técnicas de plantio. Pesquisa Agropecuária Gaúcha, Porto Alegre, v. $5, \quad$ n. 2, p.209-216, 1999. Disponível em: http://www.fepagro.rs.gov.br/upload/1398905462_art_06.pdf. Acesso em: 11 mar. 2019.

PÁDUA, E. M. M. Metodologia da pesquisa: abordagem teórico-prática. 17. ed. Campinas: Papirus, 2012. 97 p.

PONCIANO, N. J.; CONSTANTINO, C. O. R.; SOUZA, P. M.; DETMANN, E. Avaliação econômica da produção de abacaxi (Ananas comosus L.) cultivar Pérola na região Norte Fluminense. Revista Caatinga, Mossoró, v. 19, n. 1, p.82-91, 2006. Disponível em: https://www.redalyc.org/articulo.oa?id=237117486012. Acesso em: 25 fev. 2019. 
RAMBO, J. R. Produzir e vender? O caso do programa de aquisição de alimentos de agricultores familiares assentados da reforma agrária em Tangará da Serra - MT. 2016. 182 f. Tese (Doutorado em Agronomia) - Universidade Estadual Paulista "Júlio de Mesquita Filho" / UNESP, Ilha Solteira, 2016.

RAMBO, J. R.; TARSITANO, M. A. A.; KRAUSE, W.; LAFORGA, G.; SILVA, C. Análise financeira e custo de produção de banana-maçã: um estudo de caso em Tangará da Serra, estado do Mato Grosso. Informações Econômicas, São Paulo, v. 45, n. 5, p.29-39, 2015. Disponível em: http://www.iea.sp.gov.br/ftpiea/publicacoes/ie/2015/tec4-1015.pdf. Acesso em: 05 jan. 2019.

REINHARDT, D. H. R. C. Abacaxi: produção, pós-colheita e mercado. Fortaleza: Instituto Frutal, 2004. 139 p.

REINHARDT, D. H. R. C.; CUNHA, G. A. P. Propagação do abacaxizeiro. 2. ed. Brasília, DF: Embrapa Informação Tecnológica, 2006. 59 p.

REIS, L. L.; TARSITANO, M. A. A.; HIRAKI, S. S.; BARDIVIESSO, D. M. Custo de produção e rentabilidade de abacaxizeiro cv. pérola em Cassilândia (MS), sob diferentes doses de potássio. Bioscience Journal, Uberlândia, v. 28, n. 5, p.725-733, 2012. Disponível em: http://www.seer.ufu.br/index.php/biosciencejournal/article/view/13521. Acesso em: 17 fev. 2019.

SILVA, V. P.; REIS, L. M. M.; CÂNDIDO, G. A.; CARVALHO, F. G.; SILVA, R. F. Custo e lucratividade da produção de mandioca convencional versus alternativa em Bom Jesus-RN. Holos, Natal, v. 08, n. 1, p.89-103, 2017. Disponível em: http://www2.ifrn.edu.br/ojs/index.php/HOLOS/article/view/4327. Acesso em: 17 fev. 2019.

SOUZA, C. B.; SILVA, B. B.; AZEVEDO, P. V. Crescimento e rendimento do abacaxizeiro nas condições climáticas dos Tabuleiros Costeiros do Estado da Paraíba. Revista Brasileira de Engenharia Agrícola e Ambiental, Campina Grande, v. 11, n. 2, p.134-141, 2007. Disponível em: http://www.scielo.br/pdf/rbeaa/v11n2/v11n2a02.pdf. Acesso em: 13 mar. 2019.

SOUZA, O. P.; COUTINHO, A. C.; TORRES, J. L. R. Avaliação econômica da produção do abacaxi irrigado cv smooth cayenne no cerrado, em Uberaba-MG. Revista de Ciências da Vida, Seropédica, v. 30, n. 1, p.121-132, 2010. Disponível em: http://www.ufrrj.br/SEER/index.php?journal=rcv\&page=article\&op=view\&path\%5B\%5D=6 67. Acesso em: 23 mar. 2019.

TAKAGUI, C. M.; TARSITANO, M. A. A.; BOLIANI, A. C. Production cost and economic alanalysis of the pineapple crop (Ananas comosus (L.) Merril) in Guaracai, São Paulo. Revista Brasileira de Fruticultura, Cruz das Almas, v. 18, n. 2, p.219-224, 1996. Disponível em: http://agris.fao.org/agris-search/search.do?recordID=BR1997003433. Acesso em: 10 jan. 2019. 